\section{THE DEVELOPMENT OF OCCUPATIONAL HEALTH SERVICE STANDARDS FOR THE IRISH PUBLIC HEALTH SERVICE}

${ }^{1}$ Purcell Aisling*, ${ }^{2}$ McGuirk Karina, ${ }^{2}$ Taylor John. ${ }^{1}$ St. Vincent's University Hospital, Dublin, Ireland: ${ }^{2}$ Health Service Executive, Ireland

\subsection{6/oemed-2018-ICOHabstracts.952}

Introduction Participants on the Health Service Executive (HSE) Leadership Development Programme were invited to join the HSE Workplace Health and Wellbeing Unit (WHWU) Standards Project Group. The aim was to assist in the development of a framework for the standardisation of Occupational Health $(\mathrm{OH})$ service standards for the Irish public health service.

Methods The WHWU followed a practice development approach using collaboration, engagement and a bottom up and top down approach. The Standards Project Group commenced with a review of existing international $\mathrm{OH}$ standards. The Health Information and Quality Authority (HIQA) National Standards for Safer Better Healthcare were identified as the most suitable model to base these standards. A workshop was held with HIQA to discuss the best approach to developing the standards.

Membership of the group included representatives from Health and Safety, Staff Health and Wellbeing and OH services nationwide. The objectives of the group were to develop:

- $\mathrm{OH}$ specific themes within the framework

- Guides for managers and workers

- Quality Assessment and Improvement Workbooks (SelfAssessment)

Adhering to the HIQA Quality Assurance Framework (2016), the group was supported by an Expert Advisory Group made up of key internal and external stakeholders.

Result

- Interprofessional, intersectoral, integrated working -A project group representing a wide range of $\mathrm{OH}$ professionals and professionals from the wider Workplace Health and Wellbeing community was paramount to ensure shared experiences and learning.

- Use of Available Resources - International OH standards, HIQA Quality Assurance Framework, HIQA National Standards for Safer Better Healthcare, HSE Quality Assessment+Improvement workbooks, HR service user panel.

- Key Leadership Traits - Adaptability and flexibility were essential for open, effective feedback and strategy change.

- Collaboration of leadership styles and participation of high interest, high powered stakeholders was needed to ensure project success.

Conclusion The $\mathrm{OH}$ standards for the Irish public health service were launched at the Workplace Health and Wellbeing Unit Inaugural Conference on the 19th May 2017.

\section{TIME FROM ONSET OF SICKNESS ABSENCE TO MANAGEMENT REFERRAL FOR OCCUPATIONAL HEALTH ASSESSMENT IN A HEALTHCARE SETTING}

Clodagh Cashman*. BHSF Occupational Health, UK

10.1136/oemed-2018-ICOHabstracts.953
Introduction In ${ }^{1} 2016$, workers in the healthcare sector were among the groups of workers in the UK labour force who experienced the highest rates of sickness absence. Occupational health $(\mathrm{OH})^{2}$ management is advisable to facilitate workers remaining at work or returning to work (RTW) as rapidly as possible, addressing any occupational issues that may prevent RTW.

Methods An audit of all new referrals to the $\mathrm{OH}$ Physician in relation to sickness absence was undertaken during December 2016. The length of time from the onset of sickness absence to the date of management referral was noted.

Result Thirty-two cases referred by management/HR to the $\mathrm{OH}$ Physician were available for audit during the first two weeks of December 2016 in an NHS Trust $(n=9000$ employees). The referral time period from 'date of absence - date of management referral' ranged from 5 days to 3 years.

Discussion This study identifies a key factor which is important in preventing RTW for employees whose chief health conditions reflect contemporaneous ONS information, with resultant impact on the (in)direct costs of sickness absence in the healthcare sector. This audit identifies that managers vary in their referral practice and information provided. For the employer, this provides a source of feedback for managers to support ${ }^{3}$ quality improvement initiatives. Previously ${ }^{4,5}$ studies, have identified factors affecting RTW may be wide-ranging. This may have implications in relation to appropriate vocational rehabilitation or further health-related support. However further research is required to describe the factors which delay RTW in this sector, including training for management (and HR), sharing best practice when it is apparent.

\section{ORGANISATIONAL APPROACH TO OCCUPATIONAL HEALTH AND WELLBEING IN A NATIONAL REHABILITATION HOSPITAL}

${ }^{1} \mathrm{R}$ Curtis*, ${ }^{2} \mathrm{~J}$ More O'Ferrall. 'National Rehabilitation Hospital, Dublin; ${ }^{2}$ Medmark Ltd, Dublin, Ireland

\subsection{6/oemed-2018-ICOHabstracts.954}

Introduction Working in a rehabilitation facility is a demanding job, physically, psychologically and emotionally. The leadership of the National Rehabilitation Hospital

(NRH) has taken an exemplary role in addressing these risks by creating a positive working environment group to support an organisational approach to occupational health and wellbeing under the domains of, physical, psychological, environmental and social wellbeing.

Methods Several initiatives have been offered to staff under various domains. Physical Wellbeing- health screening programmes, vaccination programmes, healthy eating and weight loss programmes, physical activity programmes, smoking cessation programmes, absence management programmes. Psychological wellbeing offers staff occupational health advice and support, employee assistance programme, annual staff surveys and focus groups, staff coaching, annual staff recognition day, flexible working patterns, multiple leave options, financial advice and in house saving options. Social wellbeing encourages social gatherings and supports staff to deal with interpersonal difficulties through, dignity at work training and conflict coaching. Intellectual wellbeing in $\mathrm{NRH}$ facilitates on going education through in-house training such as mandatory and organisational trainings, grand rounds and peer reviews, full 